\title{
Comparative Research Directions of Population Initialization Techniques using PSO Algorithm
}

\author{
Sobia Pervaiz ${ }^{1}$, Waqas Haider Bangyal ${ }^{2}$, Adnan Ashraf ${ }^{3}$, Kashif Nisar ${ }^{4, *}$, Muhammad Reazul Haque ${ }^{5}$, \\ Ag. Asri Bin Ag. Ibrahim ${ }^{4}$, BS Chowdhry ${ }^{6}$, Waqas Rasheed ${ }^{7}$, Joel J. P. C. Rodrigues ${ }^{8,9}$, \\ Richard Etengu ${ }^{5}$ and Danda B. Rawat ${ }^{10}$
}

\author{
${ }^{1}$ Department of Computer Science, University of Gujrat, Gujrat, 50700, Pakistan \\ ${ }^{2}$ School of Computer Science, Beijing Institute of Technology, Beijing, 100081, China \\ ${ }^{3}$ Govt. College Women University Sialkot, Sialkot, 51310, Pakistan \\ ${ }^{4}$ Faculty of Computing and Informatics, University Malaysia Sabah, Jalan UMS, 88400, KK, Malaysia \\ ${ }^{5}$ Faculty of Computing \& Informatics, Multimedia University, Persiaran Multimedia, Cyberjaya, 63100, Selangor, Malaysia \\ ${ }^{6}$ NCRA-Condition Monitoring Systems Lab, Mehran University of Engineering \& Technology, Jamshoro, Pakistan \\ ${ }^{7}$ Department of Neurobiology and Behavior, University of California Irvine, Irvine, CA, USA \\ ${ }^{8}$ Federal University of Piauí (UFPI), Teresina, PI, Brazil \\ ${ }^{9}$ Instituto de Telecomunicações, Covilhã, 6201-001, Portugal \\ ${ }^{10}$ Department of Electrical Engineering and Computer Science, Howard University, Washington, DC, USA \\ *Corresponding Author: Kashif Nisar. Email: kashif@ums.edu.my \\ Received: 26 January 2021; Accepted: 17 April 2021
}

\begin{abstract}
In existing meta-heuristic algorithms, population initialization forms a huge part towards problem optimization. These calculations can impact variety and combination to locate a productive ideal arrangement. Especially, for perceiving the significance of variety and intermingling, different specialists have attempted to improve the presentation of meta-heuristic algorithms. Particle Swarm Optimization (PSO) algorithm is a populace-based, shrewd stochastic inquiry strategy that is motivated by the inherent honey bee swarm food search mechanism. Population initialization is an indispensable factor in the PSO algorithm. To improve the variety and combination factors, rather than applying the irregular circulation for the introduction of the populace, semiarbitrary successions are more helpful. This examination presents a thorough overview of the different PSO initialization approaches which are dependent on semi-arbitrary successions systems. In this precise review, the best in class in the populace instatement is uncovered. The procedures are classified by utilizing a theoretical model that parts the cycle of populace introduction into two phases: that is, right now expressly or certainly utilized for reinstatement in every single present approach. The deliberate investigation unveils the potential examination zones of populace introduction and, furthermore, research holes, despite the fact that the fundamental center is to give the headings to future upgrade and advancement around there. This paper gives a deliberate study identified with this calculated model for the cutting edge of exploration, which is talked about in the predefined writing to date. The study is envisioned to be useful in examining the PSO algorithm in detail for the specialist.
\end{abstract}

This work is licensed under a Creative Commons Attribution 4.0 International License, which permits unrestricted use, distribution, and reproduction in any medium, provided the original work is properly cited. 
Likewise, the paper finds the proficiency of numerous quasi-random sequences (QRS) based on initialization approaches by looking at their exhibition analyzed for sixteen notable benchmark test problems.

Keywords: PSO; swarm intelligence; artificial intelligence; low discrepancy sequences; quasi-random sequences; population initialization

\section{Introduction}

During the last three years, optimization has been an unimaginable working area of assessment better optimization algorithms were expected to manage intricate, authentic optimization problems. The main goal of optimization algorithms is to find the minimax of the objective function [1]. Swarm intelligence (SI), which is the main part of artificial intelligence (AI) [2], manages the multi-specialist framework and its underlying model that is impacted by the shared activities of social bugs like wasps, termites, ants, honey bees just as by other social creature states for example (feathered creature rushing or fish tutoring) [3]. The term SI was at first declared by Beni et al. [4] in his work on the cellular robotic framework. Scientists had been pulling into colonies of social insects for a long time, and the structure of their quantity of conduct has been covered up for quite a while. Though solitary people from these social orders are treated as non-present-day single, they have a strong ability to manage complex issues aggregately. The cooperation between the single citizen and their moderately straightforward activities upgrades their capacity to accomplish complex undertakings proficiently. SI strategies have been dynamically utilized in the field of improvement, this being of critical importance for science, engineering, robotics, and computer and telecommunication network industries. Scientists and researchers are solving future oriented network security problems in Software-Defined Networking (SDN) [5-14], Named Data Networking (NDN) [15-17], and cloud computing network [18] with future applications such as voice over IP (VoIP) [19-22] fiber optic [23-25], worldwide interoperability for microwave access (WiMAX) [26-28] with the support of SI, AI and machine learning (ML) [29]. Particle swarm optimization (PSO) is perceived as the most probable population-based stochastic algorithm, suggested by Kennedy et al. [30], which is utilized to tackle global optimization problems. Because of its power and straightforwardness, it has become the most famous procedure to tackle complex streamlining problems revealed in the differentiated fields of engineering and science. The population of candidate solutions in PSO is known as the swarm, basically charged with investigating the new search areas aggregating the movement of "flock, birds" while searching for food. In PSO, the exchange of data between all the people known as particles happen, and all the people are obliged to make disclosures about the remainder of the large number. Every individual should keep two standards, searching for getting back to its best point and bringing about the best condition of its large number. The two most basic credits are fundamental for looking through the capacity of an algorithm: investigation and misuse. The ideal outcome is measured by testing the distinctive concealed territories based on an algorithm's investigation ability. Rather than this, abuse is applied for the upgrade of all potential arrangements that are gotten by the investigation. Whereas an investigation can dispose of the neighborhood minima, misuse could heighten the pace of the algorithm. Various specialists propose that investigation ought to be done first to filter the entire region of search space followed by misuse to upgrade the arrangements made with the help of investigation [31]. The harmony among misuse and investigative capacity of population-based algorithms may watch out for high performance. A major problem with PSO and other swarm-based development algorithms is the intermingling of the swarm. Currently, analysts are trying to discover the steady bend for swarm assembly. They are searching for those ideal boundaries that assume a huge part in acquiring the ideal arrangement influenced by swarm convergence [32]. Before acquiring a global best arrangement, PSO may merge rashly, and because of this untimely conduct, PSO gets wounded into the 
neighborhood minima. To date, scientists have handled this problem by proposing to improve strategies to find the neighborhood optima problem [33]. By virtue of PSO, the zeroed-in on limits of swarm size, speed, position, inactivity weight, introduction, and intellectual factor 10 to manage nearby minima issues. The next section of the paper considers a discussion of related work. Section 3 contains the examination system. Assessment questions and overview measures are clarified in the fourth section. Results and discussion are portrayed in Section 5. End and future work are discussed in the seventh section.

\section{Literature Review}

The author in [34], presented a novel technique for the initialization of PSO global-best particle swarm with Halton grouping. Besides, a correlation is performed with the standard capacity streamlining introduced with uniform dissemination. The obtained examination results show that Holton grouping execution is superior to the uniform introduction in complex issues. In [35], the authors analyzed another technique by combining the different low-inconsistency successions, for example, Sobol, Faure, and Halton for initialization of PSO. In their work, the PSO algorithm is instated with a low discrepancy sequence to perform work improvement. Moreover, an intensive investigation was performed with various government-authorized test limits. The results were differentiated and PSO presented by uniform pseudorandom numbers. The outcomes demonstrated that by using low error for PSO introduction, upgraded the presentation of the algorithm. Besides, to deal with the global advancement in the huge dimensional spaces, the authors in [36] assessed the results of standard PSO after installing it with another low disparity arrangement named Vander Corput. The previously presented algorithm is VC-PSO, and the second is SO-PSO, which was proposed by instating PSO with Sobol group. An examination drove with the customary benchmark work. Regardless, the connection was performed with Basic Particle Swarm Optimization (BPSO) that was presented by Uniform Distribution. The results showed that proposed calculations beat especially in tremendous dimensional space issues than BPSO. The author in [37] presented the most recent improvement in PSO variants. The focus is to examine the usage and plan of the all-inclusive PSO with the assistance of Low disparity successions and different appropriations. These algorithms confirmed on different standard uni-modular, multi-modular, certifiable designing issues, and some boisterous capacities. The productivity of these checked algorithms is examined. An epic change administrator named as Sobol Mutation (SOM) administrator presented in Quantum Particle Swarm Optimization Algorithm (QPSA) for improving its exhibition called, Sobol Mutation for Quantum propelled by PSO (SOM-QPSO) [38]. SOM administrators used the Sobol arrangements from semirandom successions for the creation of another arrangement as opposed to the arbitrary dispersion. The examination of the presented algorithm was directed with QPSO, BPSO, and different adaptations of QPSO. The outcomes portrayed that the SOM administrator fittingly improves the working of QPSO. Moreover, Thangaraj et al. [39] explored the consequences of different low disparity and likelihood dispersions that were inserted with PSO. With the utilization of Sobol and Van der Corput low disparities, including Gamma, Gaussian, Beta, and Exponential likelihood circulation of the accompanying six algorithms presented: SOPSO, VCPSO, GAPSO, GPSO, EPSO, and BPSO. To confirm the exhibition of presented algorithms, standard test capacities were utilized just as the standard PSO algorithm introduced with uniform dispersion was chosen for correlation. The authentic result assumed that using low inconsistency PSO execution was agreeable. In [40] a novel altered PSO named Improved Constraint Particle Swarm Optimization (ICPSO) was presented. In the presented algorithm, a low disparity strategy called Van der Corput was used to instate the multitude in PSO. Moreover, the algorithm is not the same as the conventional PSO regarding age arrangement and refreshing the vector's position. The working of the introduced algorithm was examined through eighteen obliged test limits, which showed that the algorithm gives prevalent results for handling constrained streamlining issues. Also, to improve the exactness and union speed, another method, Particle Swarm Optimizer with randomized Quasi-random 
initialization and General Recognition [41] was proposed. The factual analysis expounded that the proposed algorithm gives extraordinary outcomes than the algorithms instated with the pseudo-random generator. To instate the particles of the multitude, the authors in [42], used low disparity groupings with the mix of social just and perception simply modular to present another variant of PSO modular. The pertinence of the proposed procedure is assessed with the six standard informational collections. Measurable outcomes exhibit that the presented procedure outperforms the Full PSO-SVM and matrix search modular. Besides, another procedure called LHNPSO was presented [43], in which a semi-random succession was utilized to instate particles, consistent speeding up coefficients, and high request non-linear time-fluctuating idleness weight. Then, Halton succession was utilized to produce the multitude. For the change of dormancy weight, social and psychological boundaries, including nonlinear capacities with enormous reach varieties were actualized. Furthermore, the two quickened constants were fixed as consistent. To examine the execution of the presented algorithm, a popular arrangement of streamlined benchmark capacities was utilized. The obtained outcome is similar to the other three PSOs' renditions. The outcome depicted that because of the considered algorithm, the union turns out to be quicker and the last arrangement is more exact than any other time. The work in [44] considered the determination of the basic purposes of multicomponent combinations as a global minimization issue of improved legitimacy work, which is intended to separate the scope of the issue. The method is applied to determine the global improvement issue. Moreover, it is isolated into two varieties of PSO outfitted by utilizing low inconsistency to diminish the intensity of the multitude identified with the underlying population area. Then an epic adjusted PSO is incorporated to overlook a quick decrement of dormancy weight and stay away from the downturn around undesirable neighborhood minima. The proposed algorithm applied different quest cycles for dormancy weight. Also, the algorithm tackled the basic issues strong and quick by utilizing global advancement. In this examination, the author [45] analyzed the effect of utilizing Halton grouping for an introduction that has a place with semi-random arrangements. By utilizing this strategy, the way toward saving the multitude's molecule conduct proclaims that the equilibrium attributes of semi-random arrangements. Measurable examinations are performed with standard capacity in high measurements to approve the productivity of the presented approach and union. In, [46] executed the low disparity Halton and Sobol successions to instate the PSO, just as an examination of the new form that is performed with standard PSO introduced by pseudo-random numbers. The thorough investigation presumed that PSO that is introduced by low inconsistent successions created effective outcomes than others. The authors in [47], proposed a novel strategy of introduction that completely works just in the polar directions. In the interim, an examination was performed to confirm the novel proposed procedure alongside standard PSO. While then again, the proposed procedure is likewise actualized to improve the exhibition of polar PSO. Also, test results are taken from the reenactment of various standard test capacities. Notwithstanding, the outcomes show that little improvement is being estimated in both PSO and polar PSO.

\section{Exploration Procedure}

The examination approach assists with characterizing the ways for leading exploration. The strategy used in this examination has played out every one of the methods for exact writing survey.

We have presented the investigation strategy for our work in Fig. 1. It depicts every one of the critical advances referred to previously. When the writing survey was directed and the hole was distinguished, and two significant requests were made to arrange the examination. These requests are expressed in our examination. Stage 2 inspects the selection of sources from which the data has been gotten. Therefore, extraordinary authentic enrolling databases have been explored and assorted request frameworks were arranged. In step 3, the decision of past examinations including articles, reviews, and papers has been driven. The cycle included distinctive filtering of studies. Out of 2000 examinations, the last channel contained 32 strategies related to our work. In sync 4, examination of disclosures and examination, the picked 32 methodologies were moved toward quality certification measures, taken from the most alluded 
to benchmark. Finally, in sync 5, all requests were answered, ensuing in wrapping up the disclosures. Results have been presented; nonetheless, discussion and future headings are furthermore given to the specialists and amateurs for coordinating significant work around there.

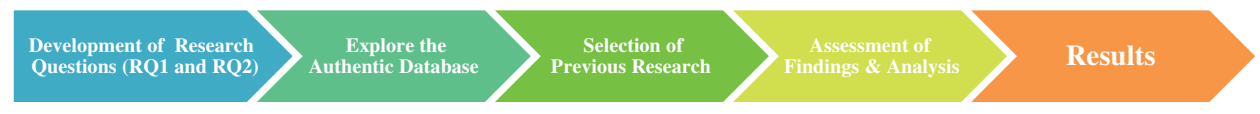

Figure 1: Exploration procedure

\section{Research Questions and Review Process}

The standards of describing overview structure have been taken from past work [48]. Under this section, two significant investigation questions have been proposed for achieving results. The figured assessment tends to the top tier QRS techniques and other instated methodologies.

\subsection{Research Questions}

It has been seen during the variety of fundamental data that various assessments are done to explore pseudo-sporadic numbers. Notwithstanding, to the most astonishing part of our knowledge, there is no examination available to cover semi-arbitrary successions for the instatement cycle of multitude insight calculations. The opening found is associated with the help of the going with the investigation question: (1) RQ1: Which presentation procedure is capable of being used for PSO that holds the assortment of the general population? (2) RQ2: What are profitable explanations that help PSO with keeping an essential separation from the pre-completely mature gathering in high dimensional space? The huge mark of this assessment is to give a conscious composing overview on the articulation pattern of the multitude insight calculation, with the help of a semi-arbitrary arrangement. The going with regions is more revolved around reacting to these requests by using past examinations.

\subsection{Selection of Data Sources and Designing Search Strategy}

The selection of data sources is one of the most crucial parts of research. It is very significant to discuss the various data sources selected for this study. Also, the designing of search data sources and the designing of search strategies are also important. In data source selection, the following data sources were selected from (1) Electronic Library of IEEE, (2) Springer Link, (3) Digital Library ACM, (4) Google Scholar. (5) Elsevier Science Direct, and (6) TSP. Some well-known databases were also approached apart from the abovementioned databases, but not included here due to the data accessibility issues. The search queries were also formed to get appropriate relevant articles. The search query for research question 1: swarm intelligence, particle swarm optimization, diversity, initialization, the population Search query for research question 2: premature convergence, local minima. After the online network database search queries, the synonyms were also used with search queries to get more results. Because of the various constraints for using a specific database in this work, each search query was designed with great care. The main purpose of designing a search strategy was to state the instructions and various checks that were followed in the collection of primary data. The list of inclusion and exclusion criteria was also adapted for the same purpose. The following are the criteria:

- All primary studies have been collected from the area of evolutionary computing algorithms and swarm intelligence.

- For better coverage of previous and relevant studies, full-length research papers and chapters from various books that are published in journal and conferences have been included for evidence-based review. 
- The data selected for this study is in English language, to address the linguistic barriers.

- To cover the latest trends in swarm intelligence of evolutionary computing algorithms, publications from the year 1995 and onwards have been included in order to get better outcome.

The authors tried to cover maximum number of studies present in the literature, which became possible due to the accessibility of several freely and openly available material supported by the Higher Education Commission (HEC) Pakistan.

\subsection{Article Selection}

Under this segment, important articles were chosen. From the outset, the conceptual and title of significant articles were perused. Subsequent to applying the second channel, full-content articles were read for the legitimacy of this examination. To eliminate excess and duplication of articles recovered from numerous information bases, further filtration and refinements were applied. In addition, the consequences of articles were guaranteed as proof-based examination.

\subsection{Procedure of Quality Assurance}

In the deliberate composing study, the congruity of articles expects a colossal work. It is basic to ensure the use of significant worth assessment methodologies for decreasing such a business. In this work, some quality assertion limits were gotten from where the benchmark inspects were picked. Moreover, these prerequisites were used in both investigation questions and are referred to later in this paper.

\subsection{Scheme of Data Extraction}

In this segment, information extraction conspire has been characterized for this work. The choice of essential information was finished by utilizing sub-area 4.3. All the applicable data and beginning information has been extricated in the wake of following the information extraction conspire. The articles were separated through the distribution subtleties, writer's subtleties, and others. The papers were investigated effectively with the quality affirmation systems.

\subsection{Plan of Data Composition}

During the article choice method, the aftereffects of the information have been arranged. In this part, the arrangement of information aggregation is examined. The articles chosen from different sources have been introduced in a plain structure. The table shows an itemized examination of the discoveries and results.

\section{Results and Discussion on QRS Bases Approaches}

The request strings were applied to various online databases and files, which required practically 4 months to wrap up. The predefined design of assessment was used to complete every movement of the review. Considering RQ1 and RQ2, starting screening yielded 989 and 1011 articles separately. Fig. 2 shows the isolating advances that were proceeded in the data arrangement procedure.

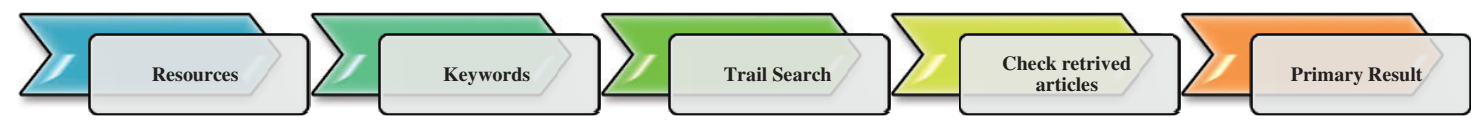

Figure 2: Strategy for data search

Whereas, Tab. 1. shows detail about list of articles that were retrieved as an outcome of the above online network database searching strategy. 
Table 1: List of articles retrieved as result of online network database searching strategy

\begin{tabular}{llllllllll}
\hline Sr. No & Data source & \multicolumn{2}{c}{ Initial scanned } & \multicolumn{2}{c}{$1^{\text {st }}$ filter } & \multicolumn{2}{c}{$2^{\text {nd }}$ filter } & \multicolumn{2}{c}{ Level } \\
\hline 1 & IEEE explore & 205 & 164 & 24 & 28 & 11 & 20 & 4 & 7 \\
2 & Google scholar & 589 & 627 & 15 & 21 & 24 & 10 & 4 & 3 \\
3 & ACM digital library & 125 & 118 & 08 & 11 & 0 & 0 & 1 & 1 \\
4 & Science direct & 46 & 58 & 5 & 8 & 5 & 5 & 2 & 3 \\
5 & Springer & 24 & 44 & 2 & 4 & 0 & 0 & 3 & 3 \\
& Total & 989 & 1011 & 54 & 72 & 40 & 35 & 14 & 18 \\
\hline
\end{tabular}

The online network database searching strategy helped to retrieve the relevant material in Tab. 1. Searching was performed in four levels including initial scan, filter 1, filter 2, and final selection. The purpose was to collect the most relevant data on RQ1 and RQ2. In the initial scan, 989 studies were collected for RQ1 and 1011 studies were collected for RQ2. In the first filtration, the refinement lead towards a total of 126 studies for both questions, which dropped to 75 in the 2nd filtration. Finally, 14 and 18 studies were finalized in the final selection. According to sub-section 4.4, the following articles were selected and shown in Tab. 2. In Tab. 2, articles were selected on the basis of relevancy to the research questions. For RQ1 14 articles were selected and for RQ2 18 articles were selected. The articles presented in Tab. 2 helped in data refinement. The data mined from primary studies were stored in a predesigned format containing general information $[49,50]$.

Table 2: Research articles selected in final filtration

\begin{tabular}{lllll}
\hline ID & Ref. No. & Articles selected for RQ1 & Ref. No. & Articles selected for RQ2 \\
\hline 1 & {$[48]$} & (K.E. Parsopoulos, 2002) & {$[49]$} & (M. Richards, 2004) \\
2 & {$[36]$} & (Millie Pant, 2008) & {$[54]$} & (H. Jabeen, 2009) \\
3 & {$[40]$} & $($ Millie Pant, 2009) & {$[55]$} & (M.S. Norouzzadeh, 2010) \\
4 & {$[33]$} & (R. Thangaraj, 2009) & {$[56]$} & (D. Jiyong, 2011) \\
5 & {$[47]$} & (M.G.H. Omran, 2013) & {$[57]$} & (R. Ngamtawee, 2012) \\
6 & {$[43]$} & (C. Yang, 2015) & {$[58]$} & (W. Gao, 2012) \\
7 & {$[51]$} & (P. Murugan, 2012) & {$[59]$} & (L. Yin, 2013) \\
8 & {$[45]$} & (G. Weerasinghe, 2016) & {$[60]$} & (C. J. Wang, 2015) \\
9 & {$[34]$} & (N. X. Hoai, 2007) & {$[61]$} & (E. V. Zyl, 2015) \\
10 & {$[35]$} & (N. Q. Uy, 2007) & {$[62]$} & (M. Corazza, 2015) \\
11 & {$[52]$} & (Millie Pant, 2009) & {$[63]$} & (M. Diez, 2016) \\
12 & {$[41]$} & (H. Li, 2010) & {$[64]$} & (A.A. Yahya, 2017) \\
13 & {$[46]$} & (S. K. Gupta, 2016) & {$[65]$} & (S. Elsayed, 2017) \\
14 & {$[53]$} & (R. Brits, 2002) & {$[66]$} & (H. Wang, 2009) \\
15 & & - & {$[67]$} & (X. Dong, 2010) \\
16 & & - & {$[52]$} & (A. L. Gutiérrez, 2011) \\
17 & & - & {$[68]$} & (M. Diez, 2014) \\
18 & & - & [69] & (B. Xue, 2014) \\
\hline
\end{tabular}


In Tab. 2, articles were selected on the basis of relevancy to the research questions. For RQ1 14 articles were selected and for RQ2 18 articles were selected. The articles presented in Tab. 2 helped in data refinement. The data mined from primary studies were stored in a pre-designed format containing general information.

\subsection{Composition of Data}

The data extracted from primary studies was composed in a way to get a meaningful and focused outcome. Different techniques were gathered and presented according to their frequency of occurrence. To improve the diversity, convergence, and robustness, quasi-random sequences are more useful to initialize the population rather than the random distribution. The identification of QRS techniques has been presented in Tab. 3, whereas, Tab. 4, the other initialization techniques are shown there.

Table 3: Identified QRS techniques

\begin{tabular}{llll}
\hline Technique & Primary study & Frequency N = 14 & Percentage (\%) \\
\hline Sobol & {$[39,47,51,35,37,41,46,54,61]$} & 9 & $64 \%$ \\
Halton & {$[47,43,45,34,35,48,41,46]$} & 8 & $57 \%$ \\
Vendar corput & {$[36,40,39,47,54,61]$} & 6 & $43 \%$ \\
Faure & {$[47,35,48,46]$} & 4 & $29 \%$ \\
NSM & {$[37,61]$} & 2 & $14 \%$ \\
Gaussian & {$[54,60]$} & 2 & $14 \%$ \\
Exponential & {$[54]$} & 1 & $7 \%$ \\
Hammersly & {$[41]$} & 1 & $7 \%$ \\
Hua-Wang & {$[41]$} & 1 & $7 \%$ \\
Log normal & {$[54]$} & 1 & $7 \%$ \\
\hline
\end{tabular}

Table 4: Identified other initialization techniques

\begin{tabular}{llll}
\hline Technique & Primary study & Frequency N = 18 & Percentage (\%) \\
\hline OBL & {$[54,43,66,51]$} & 4 & $22 \%$ \\
Orthogonal & {$[62,63,65,51,68]$} & 5 & $28 \%$ \\
STS & {$[66,67]$} & 2 & $11 \%$ \\
Chaotic & {$[57,51]$} & 2 & $11 \%$ \\
Sub-space & {$[61,67]$} & 2 & $11 \%$ \\
SIS & {$[59]$} & 1 & $6 \%$ \\
Minimax & {$[57]$} & 1 & $6 \%$ \\
CVT & {$[37,60]$} & 2 & $11 \%$ \\
Adaptive & {$[56]$} & 1 & $6 \%$ \\
FCM & {$[60]$} & 1 & $6 \%$ \\
\hline
\end{tabular}




\subsection{Identified QRS Techniques}

Initialization strategy is one of the key parameters of PSO. In PSO, the initialization of a swarm is usually done by pseudorandom numbers with the uniform distribution in search space. One issue with pseudorandom numbers is that they are not evenly distributed in space; since we didn't have any prior information about the location of optimum value. The particles of the swarm should be distributed in the space evenly so that they can efficiently find the optimum. Low-discrepancy sequences like Sobol, Halton, and Faure are more evenly distributed in the space. This section explores the answer to research question 1, where different QRS techniques have been studied and presented on the basis of primary studies. Tab. 3 shows identified techniques, their frequency, and the percentage of occurrence.

In Tab. 3, ten techniques were presented. Sobol has topped the list with frequency occurrence of 9 out of 14 having a percentage of $64 \%$. Similarly, Halton and Vendar Corrupt were in second and third place with $57 \%$ and $43 \%$ of occurrence respectively.

\subsection{Identified Other Initialization Techniques}

To dodge untimely assembly, the fundamental endeavors are centered around the optimization phase of the algorithm, for instance, the impacts on the union of the population size or the data dividing component among people. In addition, further examinations are centered around the underlying settings of the optimization algorithm to expand the achievement rate and abatement the computational expense. Sadly, as it happens in other comparable heuristic strategies, improper settings for the algorithm may prompt tricky arrangements that don't satisfy the application necessities. As of late, extraordinary instatement systems have been proposed in the writing to improve the development of population-based algorithms, on the grounds that the underlying situation of the population decides the union of the strategy. On the off chance that particles are at first situated near a worldwide ideal, the combination of the algorithm will probably accelerate. Unexpectedly, in the event that they start more like a nearby arrangement, the assembly can become wasteful or even fall flat. Tab. 4, speaks to the distinguishing proof of other instated procedures.

In Tab. 4, different initialization techniques are shown. According to the primary studies, orthogonal technique has attained first place with $28 \%$, OBL is placed at second place with $22 \%$ and frequency of occurrence 5 and 4 respectively.

\subsection{Population Initialization Techniques using Low-Discrepancy Sequences for Particle Swarm Optimization Algorithm}

Sub-sections 5.2 and 5.3 presented a detailed overview of the results shown in Tabs. 3 and 4. Firstly, choosing the initial configuration to initialize the population is one of the primary tasks in evolutionary computing as shown in Tab. 5. The performance of the evolutionary algorithm may vary due to the different fashion by firing the individuals into the search space. The swarm covers more search space; the more there is a fair chance to obtain an optimal solution. Random Initialization of population is usually employed when there is no candidate solution available. The final solution can be improved by selecting the most suitable distribution for population initialization. Researchers have been interested in adopting quasi-random and probability sequences for improving the performance of population-based evolutionary algorithms. There are three main directive principles, including:

- Swarm convergence has been considered as the dominant issue for the researchers. Therefore, many researchers have focused to determine which QRS initialization approach is more suitable for the initialization.

- QRS approaches are more suitable for enhancing the local search capability and sustaining the divergence of the population so that the algorithm will avoid local optima.

- To avoid premature convergence, QRS based initialization provides better results than uniform random initialization. 


\section{Threats to Validity}

This section describes possible threats to validate the study. There are three main threats that are needed to be mentioned here:

- The process of article selection and collection of data was manually conducted. However, the participation of all authors has minimized the risk by reducing the evaluation weakness of the selected articles.

- There was a possibility that generated results could be repeated again and again because different databases and repositories were accessed to get the data. In this regard, the criteria have been given in section III for the evaluations of research questions.

- In this systematic literature review, the authors have not proposed any model or technique. Thus, at this stage, indicative review is presented.

\section{Simulation Results}

For global optimization, the most extensive assortment of benchmark issues can be utilized. All benchmark issues have their own individual cutoff points and the course of action of point-by-point credits of such cutoff points clarifies the level of multi-layered nature for benchmark issues. For the proficiency examination of the previously mentioned QRS instatement draws near, Tab. 6, is showing the benchmark issues that are used and is clarifying the accompanying substance of benchmark problems: name, range, domain, and formulas. The exploratory delayed consequences of this work may not consider the entire competency of all assessed computations according to each possible condition. All analyses are inspected with the assistance of a PC having a processor of $2.60 \mathrm{GHz}, 16 \mathrm{~GB}$ RAM, and MATLAB $\mathrm{R} 2015 \mathrm{~b}$ is working inside Windows 8.1. It ought to be expressed that the comprehensive trial results are anticipated through 30 autonomous runs from work f1 to $\mathrm{f} 16$, having a population size of 50 .

Table 5: Experimental setting of parameters

\begin{tabular}{|c|c|c|c|c|c|}
\hline Parameters & Value & & & & \\
\hline Search space & {$[100,-100]$} & & & & \\
\hline Dimensions & 10 & 20 & 30 & 40 & 50 \\
\hline Iterations & 1000 & 2000 & 3000 & 4000 & 5000 \\
\hline Population size & 50 & & & & \\
\hline Number of PSO runs & 10 & & & & \\
\hline
\end{tabular}

Table 6: Standard benchmark functions

\begin{tabular}{|c|c|c|c|c|}
\hline $\begin{array}{l}\text { Sr. } \\
\#\end{array}$ & Function name & Objective function & Search space & Optimal value \\
\hline 01 & Sphere & $\operatorname{Minf}(x)=\sum_{i=1}^{D} x_{i}^{2}$ & $-5.12 \leq \mathrm{x}_{\mathrm{i}} \leq 5.12$ & 0 \\
\hline 02 & Rastrigin & $\operatorname{Minf}(x)=10 D+\sum_{i=1}^{D}\left[x_{i}^{2}--10 \cos (2 \pi x)\right]_{i}$ & $-5.12 \leq \mathrm{x}_{\mathrm{i}} \leq 5.12$ & 0 \\
\hline 03 & $\begin{array}{l}\text { Axis parallel } \\
\text { hyper-ellipsoid }\end{array}$ & $\operatorname{Minf}(x)=\sum_{i=1}^{D}\left(i \cdot x_{i}^{2}\right)$ & $-5.12 \leq \mathrm{x}_{\mathrm{i}} \leq 5.12$ & 0 \\
\hline 04 & $\begin{array}{l}\text { Rotated hyper } \\
\text { ellipsoid }\end{array}$ & $\operatorname{Minf}(x)=\sum_{i=1}^{D} \sum_{j=1}^{i}\left(x_{j}^{2}\right)$ & $-65.536 \leq \mathrm{x}_{\mathrm{i}} \leq 65.536$ & 0 \\
\hline
\end{tabular}




\begin{tabular}{|c|c|c|c|c|}
\hline $\begin{array}{l}\text { Sr. } \\
\#\end{array}$ & Function name & Objective function & Search space & Optimal value \\
\hline 05 & Moved axis & $\operatorname{Minf}(x)=\sum_{i=1}^{D} 5 i \cdot x_{i}^{2}$ & $-5.12 \leq \mathrm{x}_{\mathrm{i}} \leq 5.12$ & 0 \\
\hline 06 & $\begin{array}{l}\text { Sum of different } \\
\text { power }\end{array}$ & $\operatorname{Minf}(x)=\sum_{i=1}^{D}\left|x_{i}\right|^{(i+1)}$ & $-1 \leq \mathrm{x}_{\mathrm{i}} \leq 1$ & 0 \\
\hline 07 & ChungReynolds & $\operatorname{Minf}(x)=\left(\sum_{i=1}^{D} x_{i}^{2}\right)^{2}$ & $-100 \leq x_{i} \leq 100$ & 0 \\
\hline 08 & Csendes & $\operatorname{Minf}(x)=\sum_{i=1}^{D} x_{i}^{6}\left(2+\sin \frac{1}{x_{i}}\right)$ & $-1 \leq \mathrm{x}_{\mathrm{i}} \leq 1$ & 0 \\
\hline 09 & Schaffer & $\operatorname{Minf}(x)=0.5+\frac{\sin ^{2}\left(x_{1}^{2}+x_{2}^{2}\right)^{2}-0.5}{1+0.001\left(x_{1}^{2}+x_{2}^{2}\right)^{2}}$ & $-100 \leq \mathrm{x}_{\mathrm{i}} \leq 100$ & 0 \\
\hline 10 & Schumer_steiglitz & $\operatorname{Minf}(x)=\sum_{i=1}^{D} x_{i}^{4}$ & $-100 \leq \mathrm{xi} \leq 100$ & 0 \\
\hline 11 & Schwefel & $\operatorname{Minf}(x)=\left(\sum_{i=1}^{D} x_{i}^{2}\right)^{\alpha}$ & $-100 \leq \mathrm{x}_{\mathrm{i}} \leq 100$ & 0 \\
\hline 12 & Schwefel1.2 & $\operatorname{Minf}(x)=\sum_{i=1}^{D}\left(\sum_{j=1}^{i} x_{j}\right)^{2}$ & $-100 \leq \mathrm{x}_{\mathrm{i}} \leq 100$ & 0 \\
\hline 13 & Schwefel 2.21 & $\operatorname{Minf}(x)=\max _{1<i<D}\left|x_{i}\right|$ & $-100 \leq \mathrm{x}_{\mathrm{i}} \leq 100$ & 0 \\
\hline 14 & Schwefel 2.22 & $\operatorname{Minf}(x)=\sum_{i=1}^{D}\left|x_{i}\right|+\prod_{i=1}^{D}\left|x_{i}\right|$ & $-100 \leq \mathrm{x}_{\mathrm{i}} \leq 100$ & 0 \\
\hline 15 & Schwefel 2.23 & $\operatorname{Minf}(x)=\sum_{i=1}^{D} x_{i}^{10}$ & $-10 \leq \mathrm{x}_{\mathrm{i}} \leq 10$ & 0 \\
\hline 16 & Zakharov & $\begin{aligned} \operatorname{Minf}(x)= & \sum_{i=1}^{D} x_{i}^{2}+\left(\frac{1}{2} \sum_{i=1}^{n} i x_{i}\right)^{2} \\
& +\left(\frac{1}{2} \sum_{i=1}^{n} i x_{i}\right)^{4}\end{aligned}$ & $-5 \leq \mathrm{x}_{\mathrm{i}} \leq 10$ & 0 \\
\hline
\end{tabular}

Table 7: Comparative results for SO-PSO, H-PSO, TO-PSO, WE-PSO, KE-PSO

\begin{tabular}{llllllll}
\hline \multirow{2}{*}{ Functions } & \multirow{2}{*}{ DIM X Itr } & PSO & SO-PSO & H-PSO & TO-PSO & WE-PSO & \multicolumn{2}{l}{ KN-PSO } \\
& & Mean & Mean & Mean & Mean & Mean & Mean \\
\hline $\mathbf{F 1}$ & $\mathbf{1 0 0 0}$ & $2.33 \mathrm{E}-74$ & $2.74 \mathrm{E}-76$ & $3.10 \mathrm{E}-77$ & $\mathbf{5 . 5 7 E}-\mathbf{7 8}$ & $\mathbf{5 . 9 1 E}-\mathbf{7 8}$ & $0.0000 \mathrm{E}+00$ \\
& $\mathbf{2 0 0 0}$ & $1.02 \mathrm{E}-84$ & $8.20 \mathrm{E}-88$ & $1.76 \mathrm{E}-90$ & $\mathbf{1 . 3 0 E}-\mathbf{9 0}$ & $4.95 \mathrm{E}-90$ & $3.14001 \mathrm{E}-217$ \\
& $\mathbf{3 0 0 0}$ & $1.77 \mathrm{E}-26$ & $7.67 \mathrm{E}-20$ & $4.13 \mathrm{E}-32$ & $\mathbf{1 . 2 5 E}-\mathbf{5 1}$ & $\mathbf{1 . 3 0 E}-\mathbf{4 2}$ & $8.91595 \mathrm{E}-88$ \\
$\mathbf{F 2}$ & $\mathbf{1 0 0 0}$ & $4.97 \mathrm{E}-01$ & $4.97 \mathrm{E}-01$ & $7.96 \mathrm{E}-01$ & $\mathbf{3 . 9 8 E}-\mathbf{0 1}$ & $\mathbf{2 . 9 8 E}-\mathbf{0 1}$ & -8602.02 \\
& $\mathbf{2 0 0 0}$ & $8.17 \mathrm{E}+00$ & $6.47 \mathrm{E}+00$ & $3.58 \mathrm{E}+00$ & $\mathbf{2 . 8 9 E}+\mathbf{0 0}$ & $\mathbf{3 . 1 1 E}+\mathbf{0 0}$ & -31433.3 \\
& $\mathbf{3 0 0 0}$ & $1.01 \mathrm{E}+01$ & $9.86 \mathrm{E}+00$ & $9.45 \mathrm{E}+00$ & $\mathbf{8 . 1 6 E}+\mathbf{0 0}$ & $\mathbf{7 . 7 6 E}+\mathbf{0 0}$ & -60711.8 \\
$\mathbf{F 3}$ & $\mathbf{1 0 0 0}$ & $8.70 \mathrm{E}-80$ & $1.79 \mathrm{E}-79$ & $4.87 \mathrm{E}-79$ & $\mathbf{3 . 9 1 E}-\mathbf{8 2}$ & $\mathbf{4 . 4 0 E}-\mathbf{8 1}$ & $0.0000 \mathrm{E}+00$ \\
& $\mathbf{2 0 0 0}$ & 2.62144 & 7.86432 & 2.62144 & $\mathbf{7 . 0 7 E}-\mathbf{9 0}$ & $\mathbf{1 . 7 8 E}-\mathbf{8 9}$ & $4.78718 \mathrm{E}-237$ \\
& $\mathbf{3 0 0 0}$ & $2.62 \mathrm{E}+01$ & $1.57 \mathrm{E}+01$ & $1.05 \mathrm{E}+01$ & $\mathbf{7 . 7 0 E}-\mathbf{3 5}$ & $\mathbf{3 . 8 7 E}-\mathbf{5 7}$ & $1.57084 \mathrm{E}-97$ \\
$\mathbf{F 4}$ & $\mathbf{1 0 0 0}$ & $4.46 \mathrm{E}-147$ & $3.86 \mathrm{E}-147$ & $9.78 \mathrm{E}-145$ & $\mathbf{7 . 2 9 E}-\mathbf{1 4 8}$ & $\mathbf{1 . 2 4 E}-\mathbf{1 5 0}$ & $0.0000 \mathrm{E}+00$ \\
& $\mathbf{2 0 0 0}$ & $3.14 \mathrm{E}-155$ & $9.27 \mathrm{E}-154$ & $\mathbf{2 . 7 5 E}-\mathbf{1 5 9}$ & $5.14 \mathrm{E}-158$ & $4.96 \mathrm{E}-159$ & $0.0000 \mathrm{E}+00$ \\
& $\mathbf{3 0 0 0}$ & $1.82 \mathrm{E}-133$ & $2.36 \mathrm{E}-135$ & $8.53 \mathrm{E}-130$ & $\mathbf{3 . 1 3 E}-\mathbf{1 3 8}$ & $\mathbf{2 . 5 4 E}-\mathbf{1 3 6}$ & $1.6439 \mathrm{E}-228$ \\
\hline
\end{tabular}




\begin{tabular}{|c|c|c|c|c|c|c|c|}
\hline Functions & DIM X Itr & $\begin{array}{l}\text { PSO } \\
\text { Mean }\end{array}$ & $\begin{array}{l}\text { SO-PSO } \\
\text { Mean }\end{array}$ & $\begin{array}{l}\text { H-PSO } \\
\text { Mean }\end{array}$ & $\begin{array}{l}\text { TO-PSO } \\
\text { Mean }\end{array}$ & $\begin{array}{l}\text { WE-PSO } \\
\text { Mean }\end{array}$ & $\begin{array}{l}\text { KN-PSO } \\
\text { Mean }\end{array}$ \\
\hline \multirow[t]{3}{*}{ F5 } & 1000 & $4.35 \mathrm{E}-79$ & $8.95 \mathrm{E}-79$ & $2.43 E-78$ & $2.04 E-80$ & $2.20 E-80$ & $0.0000 \mathrm{E}+00$ \\
\hline & 2000 & $1.31 \mathrm{E}+01$ & $3.93 \mathrm{E}+01$ & $1.31 \mathrm{E}+01$ & $3.54 E-89$ & $3.12 E-89$ & $2.39359 \mathrm{E}-236$ \\
\hline & 3000 & $1.31 \mathrm{E}+02$ & $7.86 \mathrm{E}+01$ & $5.24 \mathrm{E}+01$ & $3.85 E-34$ & $1.94 E-56$ & $2.9093 E-87$ \\
\hline \multirow[t]{3}{*}{ F6 } & 1000 & $1.70 \mathrm{E}-61$ & $4.45 \mathrm{E}-64$ & $7.29 \mathrm{E}-66$ & $2.46 E-66$ & $4.62 E-66$ & $3.04226 \mathrm{E}-318$ \\
\hline & 2000 & $3.25 \mathrm{E}-112$ & $4.39 \mathrm{E}-112$ & $5.01 \mathrm{E}-109$ & $2.56 E-115$ & $4.45 \mathrm{E}-113$ & $8.59557 \mathrm{E}-277$ \\
\hline & 3000 & $7.21 \mathrm{E}-135$ & $4.10 \mathrm{E}-124$ & $1.51 \mathrm{E}-134$ & $6.22 E-137$ & $6.96 E-135$ & $2.33033 \mathrm{E}-223$ \\
\hline \multirow[t]{3}{*}{ F7 } & 1000 & $2.96 \mathrm{E}-157$ & $2.39 \mathrm{E}-157$ & $1.28 \mathrm{E}-157$ & $4.89 E-159$ & $2.47 E-163$ & $0.0000 \mathrm{E}+00$ \\
\hline & 2000 & $8.79 \mathrm{E}-177$ & $1.77 \mathrm{E}-184$ & $3.49 \mathrm{E}-183$ & $3.09 E-187$ & $3.41 E-186$ & $0.0000 \mathrm{E}+00$ \\
\hline & 3000 & $1.23 \mathrm{E}-82$ & $1.25 \mathrm{E}-116$ & $5.99 \mathrm{E}-130$ & $5.01 E-135$ & $4.60 \mathrm{E}-134$ & $8.03288 \mathrm{E}-175$ \\
\hline \multirow[t]{3}{*}{ F8 } & 1000 & $4.39 \mathrm{E}-200$ & $1.98 \mathrm{E}-194$ & $4.51 \mathrm{E}-197$ & $1.26 E-202$ & $8.99 E-201$ & $4.9228 E-67$ \\
\hline & 2000 & $1.57 \mathrm{E}-20$ & $1.04 \mathrm{E}-93$ & $1.10 \mathrm{E}-148$ & $2.84 E-157$ & $4.09 E-151$ & $4.5887 \mathrm{E}-16$ \\
\hline & 3000 & $1.89 \mathrm{E}-09$ & $4.54 \mathrm{E}-10$ & $1.14 \mathrm{E}-08$ & $1.40 \mathrm{E}-10$ & $1.34 \mathrm{E}-09$ & $2.2334 \mathrm{E}-08$ \\
\hline \multirow[t]{3}{*}{ F9 } & 1000 & $5.49 \mathrm{E}-01$ & $1.30 \mathrm{E}-01$ & $2.02 \mathrm{E}-01$ & $1.26 \mathrm{E}-01$ & $1.42 \mathrm{E}-01$ & 0.824968 \\
\hline & 2000 & $2.05 \mathrm{E}+00$ & $7.83 \mathrm{E}-01$ & $6.83 \mathrm{E}-01$ & $5.84 E-01$ & $4.32 E-01$ & 4.56265 \\
\hline & 3000 & $1.12 \mathrm{E}+00$ & $9.99 \mathrm{E}-01$ & $9.56 \mathrm{E}-01$ & $9.06 E-01$ & $9.12 E-01$ & 7.25675 \\
\hline \multirow[t]{3}{*}{ F10 } & 1000 & $2.23 E-138$ & $2.23 \mathrm{E}-138$ & $4.35 E-137$ & $1.02 E-140$ & $1.10 E-139$ & $0.0000 \mathrm{E}+00$ \\
\hline & 2000 & $3.79 \mathrm{E}-148$ & $7.87 \mathrm{E}-149$ & $4.19 \mathrm{E}-147$ & $3.78 E-151$ & $8.73 E-153$ & $0.0000 \mathrm{E}+00$ \\
\hline & 3000 & $4.43 E-126$ & $7.52 \mathrm{E}-133$ & $1.57 \mathrm{E}-128$ & $2.03 E-134$ & $1.38 E-133$ & $2.26229 \mathrm{E}-221$ \\
\hline \multirow[t]{3}{*}{ F11 } & 1000 & $3.75 \mathrm{E}-187$ & $1.57 \mathrm{E}-192$ & $2.15 \mathrm{E}-191$ & $5.57 E-198$ & $8.99 E-198$ & $0.0000 \mathrm{E}+00$ \\
\hline & 2000 & $5.29 \mathrm{E}-193$ & $2.53 E-195$ & $8.45 \mathrm{E}-195$ & $8.45 \mathrm{E}-195$ & $9.83 E-197$ & $0.0000 \mathrm{E}+00$ \\
\hline & 3000 & $4.82 \mathrm{E}-154$ & $8.84 \mathrm{E}-159$ & $5.49 \mathrm{E}-168$ & $2.04 E-170$ & $5.75 E-173$ & $9.00586 \mathrm{E}-278$ \\
\hline \multirow[t]{3}{*}{ F12 } & 1000 & $1.13 \mathrm{E}-01$ & $1.67 \mathrm{E}-02$ & $2.28 \mathrm{E}-02$ & $4.78 E-03$ & $2.89 E-03$ & $2.739 \mathrm{E}-12$ \\
\hline & 2000 & $1.39 \mathrm{E}+01$ & $5.03 \mathrm{E}+00$ & $2.95 \mathrm{E}+00$ & $1.28 \mathrm{E}+00$ & $1.67 E+00$ & $7.819 \mathrm{E}+00$ \\
\hline & 3000 & $7.45 \mathrm{E}+00$ & $1.22 \mathrm{E}+01$ & $8.74 \mathrm{E}+00$ & $2.94 \mathrm{E}+00$ & $4.94 E+00$ & $2.239 \mathrm{E}+01$ \\
\hline \multirow[t]{3}{*}{ F13 } & 1000 & $8.04 \mathrm{E}-26$ & $8.01 \mathrm{E}-27$ & $3.59 \mathrm{E}-27$ & $1.24 E-27$ & $1.41 E-27$ & $0.0000 \mathrm{E}+00$ \\
\hline & 2000 & $1.42 \mathrm{E}-08$ & $2.64 E-11$ & $3.29 \mathrm{E}-10$ & $2.99 \mathrm{E}-10$ & $2.14 E-12$ & $0.0000 \mathrm{E}+00$ \\
\hline & 3000 & $6.20 \mathrm{E}-03$ & $1.41 \mathrm{E}-03$ & $9.36 \mathrm{E}-03$ & $1.12 E-03$ & $1.41 E-03$ & $0.0000 \mathrm{E}+00$ \\
\hline \multirow[t]{3}{*}{ F14 } & 1000 & $3.62 \mathrm{E}-38$ & $3.62 \mathrm{E}-38$ & $5.92 \mathrm{E}-36$ & $6.92 E-39$ & $1.95 E-38$ & $7.78286 \mathrm{E}-197$ \\
\hline & 2000 & $6.27 \mathrm{E}-10$ & $1.38 \mathrm{E}-09$ & $7.91 E-13$ & $2.49 \mathrm{E}-12$ & $1.17 E-13$ & $6.6163 \mathrm{E}-12$ \\
\hline & 3000 & $2.56 \mathrm{E}-06$ & $4.80 \mathrm{E}+01$ & $1.34 \mathrm{E}-06$ & $5.40 \mathrm{E}-11$ & $4.88 E-09$ & $9.3032 \mathrm{E}-06$ \\
\hline \multirow[t]{3}{*}{ F15 } & 1000 & $1.10 \mathrm{E}-294$ & $3.19 \mathrm{E}-301$ & $2.78 \mathrm{E}-307$ & $1.94 E-307$ & $3.21 E-308$ & $6.26612 \mathrm{E}-138$ \\
\hline & 2000 & $6.16 \mathrm{E}-271$ & $5.09 \mathrm{E}-276$ & $3.74 \mathrm{E}-270$ & $1.60 E-276$ & $4.85 \mathrm{E}-268$ & $1.29033 \mathrm{E}-25$ \\
\hline & 3000 & $3.08 \mathrm{E}-207$ & $1.04 \mathrm{E}-200$ & $8.12 \mathrm{E}-209$ & $2.34 E-215$ & $3.06 E-212$ & $2.27 \mathrm{E}-06$ \\
\hline \multirow[t]{3}{*}{ F16 } & 1000 & 5.4835385 & $8.5299 \mathrm{E}-17$ & $3.3074 \mathrm{E}-16$ & 1.224803 & $8.3354 \mathrm{E}-07$ & $2.26476 \mathrm{E}-27$ \\
\hline & 2000 & 83.467 & 1.6344 & 0.18037 & 49.16841 & 5.1322 & $7.17014 \mathrm{E}-72$ \\
\hline & 3000 & 265.90708 & 282.1864 & 45.0408 & 133.9679 & 67.0301 & $5.45179 \mathrm{E}-251$ \\
\hline
\end{tabular}


IASC, 2022, vol.32, no.3

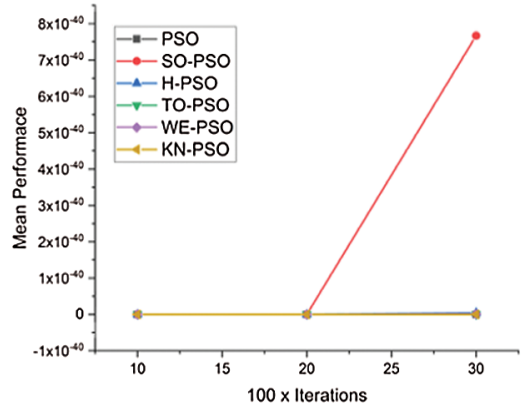

F1

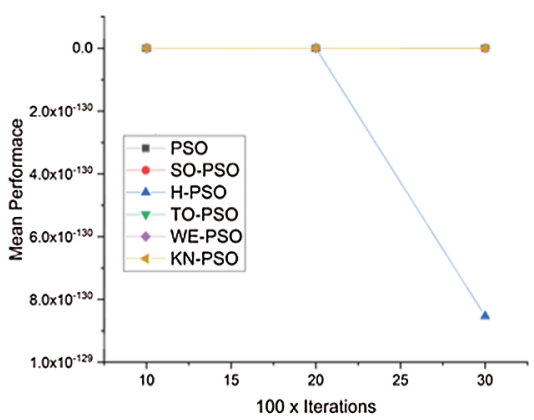

F4

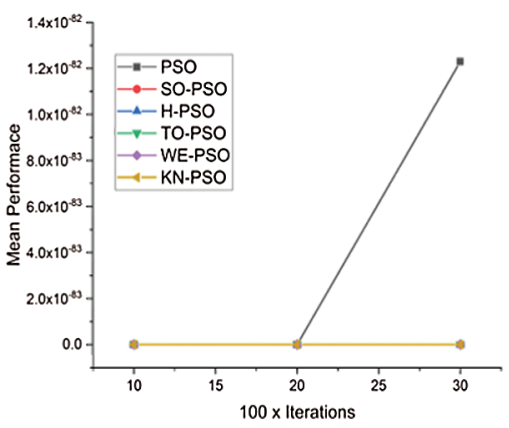

F7

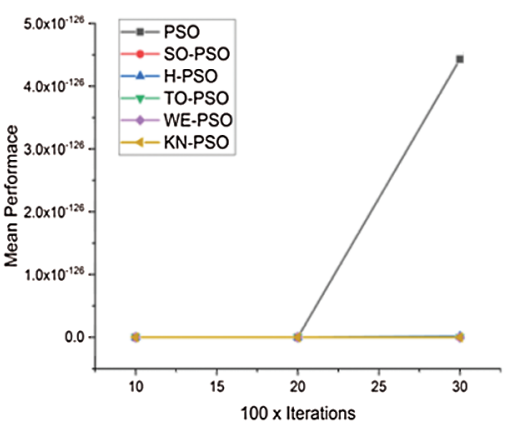

F10

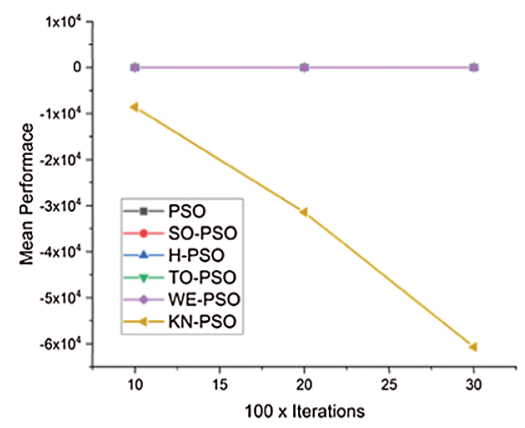

F2

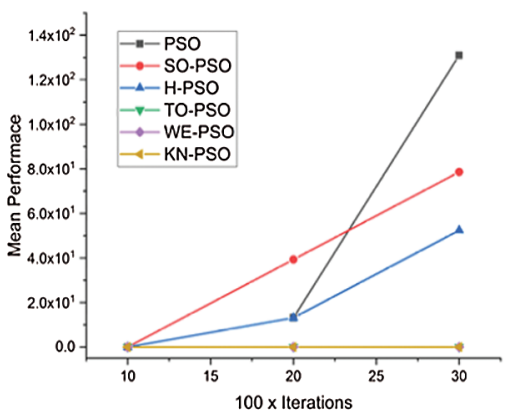

F5

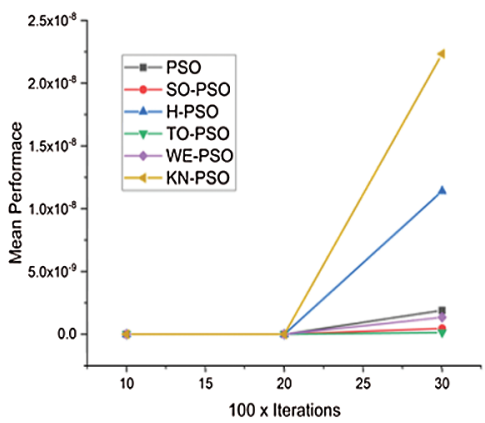

F8

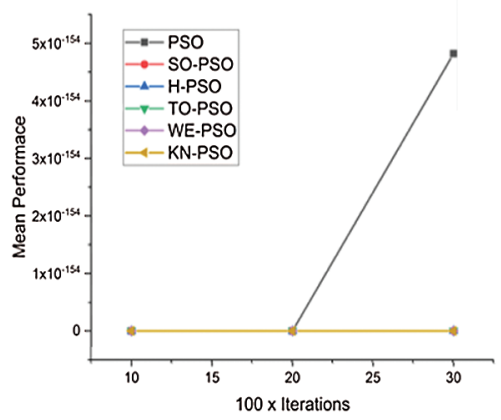

F11

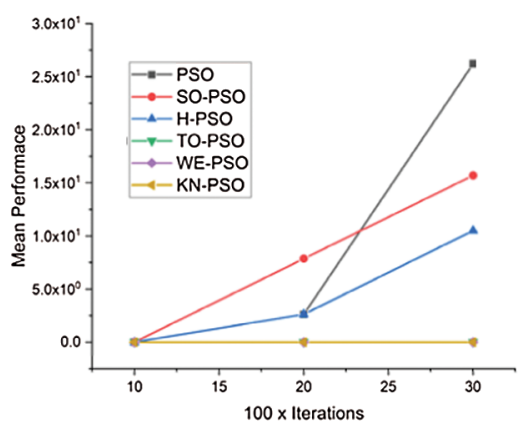

F3

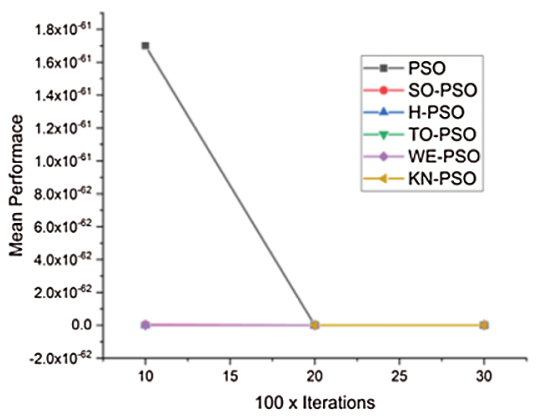

F6

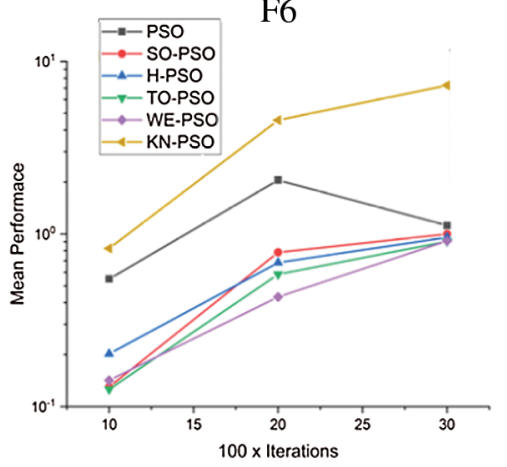

F9

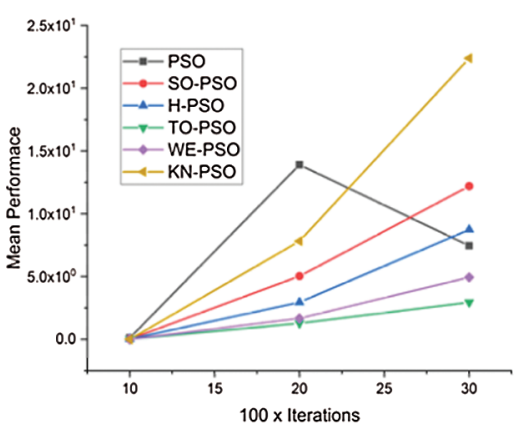

F12

Figure 3: Continued 


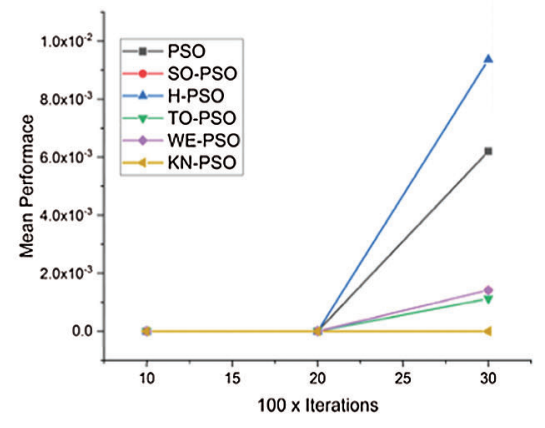

F13

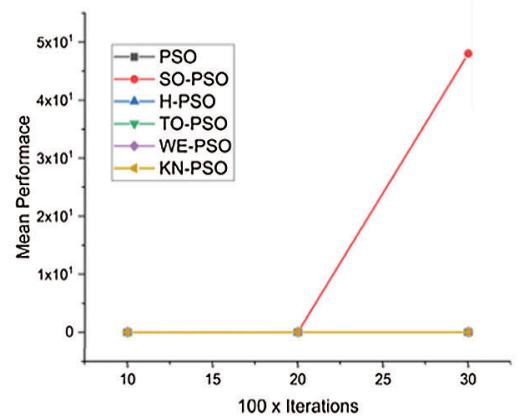

F14

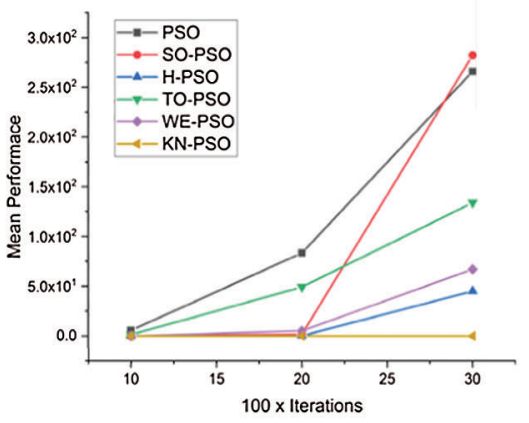

F16

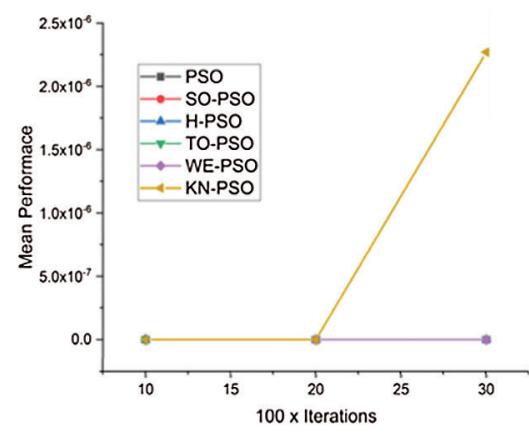

F15

\subsection{Convergence Graphs}

In this part, the refined results are demonstrated by the blending graph of the mean wellness assessment of all limits from F1 to F16 and depict the achievements of different QRS approaches as for their productivity and capacity.

\subsection{Discussion}

From Fig. 3, the Figures, unmistakably the presentation of the methodologies SO-PSO, H-PSO, TOPSO, WE-PSO, KE-PSO, and customary PSO is looked at for fifteen benchmark capacities. In the diagrams, the level center point is showing the total number of accentuations, while, of course the vertical center point is showing the mean assessment of target limits at the fixed number of capacity algorithms. Correspondingly, the value achieved in each cycle has functioned as a show measure. Therefore, the abuse capacity of customary PSO is modestly low, especially for high-dimensional issues. The outcomes are additionally revealed that QRS based on instated PSO is just viable in execution, while they are handling costly plan issues having low dimensionality. Other than this, KE-PSO has fantastic control on the high dimensionality issues than different strategies notwithstanding the intricacy and the shallow geography of the inspected issues as shown in Tab. 7. The outcomes are exhibited that KE-PSO beats in higher dimensionality issues. By summing up, the dimensionality emphatically impacts the working of most algorithms. In any case, it is seen that KE-PSO is more reliable during the addition of measurements of the issue. Because of this consistency of QRS based instatement, it is demonstrated that the QRS based introduced algorithm has the more noteworthy ability of investigation. To assess the adequacy of QRS based on introduction draws near, it is applied to limit 15 benchmark capacities with various attributes, including plans, limits of search space, worldwide fewest qualities. These benchmark test capacities are broadly utilized to test the presentation of worldwide enhancement. To 
comprehensively check the proficiency of all QRS bases, its adequacy is contrasted and the conventional PSO and other QRS based methodologies. The halting measures for all algorithms ensure that the most extreme cycle is reached by the greatest number of emphases. For all benchmark capacities, every algorithm is exclusively run multiple times with every algorithm.

\section{Conclusion}

Much as PSO method has been widely used in various areas to solve real world non-linear complex optimization problems, the approach still needs further investigation to ensure performance enhancement. Currently, the researcher has suggested various variants for the PSO approach. The survey gives an exhaustive coverage of the initialization strategies used for different PSO approaches to resolve the local minima problem of premature convergence to attain the best results. We have covered different initialization strategies and analyzed each initialization technique separately. With the rising popularity of this research area, there are high expectations that more research will be undertaken with perfection in the next few years. The survey is anticipated to provoke additional research interest to simulate the fundamental recognition of how PSO initialization strategies enhance the performance of standard PSO. We believe such an understanding will encourage such researchers to work towards advancement of particular PSOs or better still formulate new ones.

Funding Statement: The authors received no specific funding for this study.

Conflicts of Interest: The authors have no conflicts of interest to report regarding the present study.

\section{References}

[1] V. Bhaskar, S. K. Gupta and A. K. Ray, "Applications of multi objective optimization in chemical engineering," Ph.D. dissertation. Department of Chemical Engineering, National University of Singapore, Singapore, 2000.

[2] M. R. Haque, S. C. Tan, Z. Yusoff, K. Nisar, C. K. Lee et al., "SDN architecture for UAVs and EVs using satellite: A hypothetical model and new challenges for future," in IEEE CCNC, Las Vegas, NV, USA, pp. 1-6, 2021.

[3] C. Blum and X. Li, "Swarm intelligence in optimization," in Swarm Intelligence. Berlin Heidelberg: SpringerVerlag, pp. 43-85, 2008.

[4] G. Beni and J. Wang, Swarm Intelligence in Cellular Robotic Systems, in Robots and Biological Systems: Towards a New Bionics?. Berlin, Germany: Springer, pp. 703-712, 1993.

[5] K. Nisar, A. M. Said and H. Hasbullah, Enhanced Performance of Packet Transmission using System Model Over Voip Network. Kuala Lumpur, Malaysia: IEEE International Symposium on Information Technology, pp. 10051008, 2010.

[6] K. Nisar, E. R. Jimson, M. H. A. Hijazi, I. Welch, R. Hassan et al., "A survey on the architecture, application and security of software defined networking," Internet of Things, vol. 12, pp. 1-27, 2020.

[7] K. Nisar, E. R. Jimson, M. H. A. Hijazi and S. K. Memon, "A survey: Architecture, security threats and application of SDN," Journal of Industrial Electronics Technology and Application, Daegu University, Republic of Korea, vol. 2, no. 1, pp. 64-69, 2019.

[8] M. R. Haque, S. C. Tan, Z. Yusoff, K. Nisar, C. K. Lee et al., Automated Controller Placement for SoftwareDefined Networks to Resist DDoS Attacks, Computers. USA: Materials \& Continua, Tech Science Press, 2021.

[9] K. Nisar, G. Chen and A. Sarrafzadeh, "A review: Software defined networks management," network research workshop," APAN, vol. 39, pp. 1-9, 2015.

[10] M. R. Haque, S. C. Tan, Z. Yusoff, C. K. Lee, S. Ali et al., "Motivation of DDoS attack-aware in software defined networking controller placement," in IEEE ICCA. Dubai, 36-42, 2017.

[11] N. F. Ali, A. M. Said, K. Nisar and I. A. Aziz, "A survey on software defined network approaches for achieving energy efficiency in wireless sensor network," in IEEE Conf. on Wireless Sensors (ICWiSe), Miri, Malaysia, pp. 28-33, 2017. 
[12] K. Nisar, M. H. A. Hijazi and A. A. A. Ibrahim, "A new model for virtual machine migration with software defined networking," in CSCEET2017, Beirut, Lebanon, 2017.

[13] M. R. Haque, S. C. Tan, C. K. Lee, Z. Yusoff, S. Ali et al., "Analysis of DDoS attack-aware software-defined networking controller placement in Malaysia," in Recent Trends in Computer Applications, J. Alja'am, A. El Saddik, A. Sadka (eds.), Cham, Switzerland: Springer International Publishing AG, Springer Nature, pp. 175$188,2018$.

[14] E. R. Jimson, K. Nisar and M. H. Ad Hijazi, "The state of the art of software defined networking (SDN) issues in current network architecture and a solution for network management using the SDN," International Journal of Technology Diffusion, (IJTD), IGI Global Publishers, Hershey, PA, USA, vol. 10, pp. 33-48, 2019.

[15] A. A. A. Ibrahim and K. Nisar, "Future internet and named data networking hourglass, packet and node architecture," Journal of Industrial Information Technology and Application, Daegu University, Republic of Korea, vol. 2, pp. 115-123, 2018.

[16] S. Zhang, Z. Yan, Y. Park, H. Nakazatod, W. Kameyama et al., "Efficient producer mobility support in named data networking," The Institute of Electronics, Information and Communication Engineers, the IEICE Transactions, Tokyo, Japan, vol. E100-B, no. 10, pp. 1856-1864, 2017.

[17] S. Harada, Z. Zan, Y. Park, K. Nisar and A. A. A. Ibrahim, "Data aggregation in named data networking," in IEEE Region 10 Conf. (TENCON), Penang, Malaysia, pp. 1839-1842, 2017.

[18] Y. Zhang, X. Lan, J. Ren and L. Cai, "Efficient computing resource sharing for mobile edge-cloud computing networks," IEEE/ACM Transactions on Networking, vol. 28, no. 3, pp. 1227-1240, 2020.

[19] K. Nisar, A. Amphawan, S. Hassan and N. I. Sarkar, "A comprehensive survey on scheduler for VoIP over WLANs," Journal of Network and Computer Applications, vol. 36, no. 2, pp. 933-948, 2013.

[20] F. Sattar, M. Hussain and K. Nisar, "A secure architecture for open source VoIP solutions," in Int. Conf. on Information and Communication Technologies, Karachi, pp. 1-6, 2011.

[21] K. Nisar, A. M. Said and H. Hasbullah, "Enhanced performance of packet transmission using system model over VoIP network," in Int. Symp. on Information Technology 2010 (ITSim 2010), IEEE 2010, KLCC, Kuala Lumpur, Malaysia, pp. 1005-1008, 2010.

[22] N. I. Sarkar, K. Nisar and L. Babbage, "Performance studies on campus-wide focus on FTP, video and VoIP ethernet network," International Journal of Advanced Pervasive and Ubiquitous Computing, (IJAPUC), IGI Global Publishers, Hershey, PA, USA, vol. 4, no. 1, pp. 49-59, 2012.

[23] B. S. Chaudhary, A. Amphawan and K. Nisar, "Realization of free space optics with OFDM under atmospheric turbulence," Optik, vol. 125, no. 18, pp. 5196- 5198, 2014.

[24] A. Amphawan, V. Mishra, K. Nisar and B. Nedniyom, "Real-time holographic backlighting positioning sensor for enhanced power coupling efficiency into selective launches in multimode fiber," Journal of Modern Optics, UK, vol. 59, no. 20, pp. 1745-1752, 2012.

[25] R. Singh and G. Soni, "Realization of OFDM based free space optics," in Int. Conf. on Green Computing and Internet of Things (ICGCIoT), Noida, pp. 32-35, 2015.

[26] J. Shuja, R. W. Ahmad, A. Gani, A. I. A. Ahmed, A. Siddiqa et al., "Greening emerging IT technologies: Techniques and practices," Journal of Internet Services and Applications (JISA), Springer, London, UK, vol. 8, no. 9, pp. 1-11, 2017.

[27] I. A. Lawal, A. M. Said, K. Nisar and A. A. Mu'azu, "A distributed QoS-oriented model to improve network performance for fixed WiMAX," International. Journal on Recent Trends in Engineering and Technology, Association of Computer Electronics and Electrical Engineers, vol. 10, no. 1, pp. 186-202, 2014.

[28] I. A. Lawal, A. M. Said, K. Nisar, P. A.Shah and A. R. A. Mu'azu, "Throughput performance improvement for VoIP applications in fixed WiMAX network using client-server model," Journal of Science International-Lahore, Pakistan, vol. 26, no. 3, pp. 999-1002, 2014.

[29] M. R. Haque, S. C. Tan, Z. Yusoff, K. Nisar, C. K. Lee et al., "A novel DDoS attack-aware smart backup controller placement in SDN design," Annals of Emerging Technologies in Computing, vol. 4, no. 5, pp. 75-92, 2020.

[30] J. Kennedy and R. Eberhart, "Particle swarm optimization," Proceedings of ICNN'95-International Conference on Neural Networks, WA, Australia, vol. 4, pp. 1942-1948, 1995. 
[31] G. Rudolph, "Self-adaptive mutations may lead to premature convergence," IEEE Transactions on Evolutionary Computation, vol. 5, no. 4, pp. 410-414, 2001.

[32] M. Z. Rehman, A. Khan, H. Chiroma and T. Herawan, "A modified bat algorithm based on Gaussian distribution for solving optimization problem," Journal of Computational and Theoretical Nanoscience, American Scientific Publishers, USA, vol. 13, pp. 706-714, 2016.

[33] P. Kora and S. R. Kalva, "Improved bat algorithm for the detection of myocardial infarction," SpringerPlus Springer, vol. 4, no. 1, pp. 666, 2015.

[34] X. H. Nguyen, Q. U. Nguyen and R. I. Mckay, "PSO with randomized low-discrepancy sequences," in Proc. of the 9th annual conf. on Genetic and Evolutionary Computation, New York, New York, United States, ACM, pp. 173, 2007.

[35] N. Q. Uy, N. X. Hoai, R. McKay and P. M. Tuan, "Initialising PSO with randomised low-discrepancy sequences: the comparative results," in IEEE Congress on Evolutionary Computation, Singapore, pp. 1985-1992, 2007.

[36] M. Pant, R. Thangaraj and V. Singh, "Sobol mutated quantum particle swarm optimization," International Journal of Recent Trends in Engineering, Academy Publisher, vol. 1, pp. 95, 2009.

[37] M. Pant, R. Thangaraj and A. Abraham, "Particle swarm optimization: Performance tuning and empirical analysis," in Foundations of Computational Intelligence. vol. 3. Berlin, Germany: Springer, pp. 101-128, 2009.

[38] M. Pant, R. Thangaraj, C. Grosan and A. Abraham, "Improved particle swarm optimization with low-discrepancy sequences," in IEEE Congress on Evolutionary Computation (IEEE World Congress on Computational Intelligence), Hong Kong, pp. 3011-3018, 2008.

[39] R. Thangaraj, M. Pant and K. Deep, "Initializing PSO with probability distributions and low-discrepancy sequences: The comparative results," in 2009 World Congress on Nature \& Biologically Inspired Computing, Piscataway, New Jersey, United States, IEEE, pp. 1121-1126, 2009.

[40] M. Pant, R. Thangaraj and A. Abraha, "Low discrepancy initialized particle swarm optimization for solving constrained optimization problems," Fundamenta Informaticae, vol. 95, no. 4, pp. 511-531, 2009.

[41] H. Li and X. Wu, "A particle swarm optimizer with randomized quasi-random and general recognition," in 3rd Int. Conf. on Advanced Computer Theory and Engineering, Chengdu, vol. 4, pp. 4-154, 2010.

[42] D. H. Nghi and L. C. Mai, "A new model of particle swarm optimization for model selection of support vector machine," in New Challenges for Intelligent Information and Database Systems. Berlin, Germany: Springer, pp. 167-173, 2011.

[43] C. Yang, W. Gao, N. Liu and C. Song, "Low-discrepancy sequence initialized particle swarm optimization algorithm with high-order nonlinear time-varying inertia weight," Applied Soft Computing, vol. 29, no. 4, pp. 386-394, 2015.

[44] N. Henderson, D. M. Menezes and A. A. Sacco, "Computation of critical points of mixtures using particle swarm optimization with low-discrepancy sequences," Chemical Eng. Comm, vol. 202, no. 11, pp. 1478-1492, 2015.

[45] X. H. Nguyen, Q. U. Nguyen and R. I. Mckay, "PSO with randomized low-discrepancy sequences," in Proc. of the 9th annual conference on Genetic and evolutionary computation, New York, New York, United States, ACM, pp. 173, 2007.

[46] S. K. Gupta, S. Arora and Nayak, Efficient initialization of particle swarm optimization using low discrepancy sequence. In: Advances in Intelligent Systems and Computing. Berlin, Germany: Springer, pp. 440-449, 2016.

[47] M. Shatnawi, M. F. Nasrudin and S. Sahran, "A new initialization technique in polar coordinates for particle swarm optimization and polar PSO," International Journal on Advanced Science, Engineering and Information Technology, vol. 7, no. 1, pp. 242-249, 2017.

[48] M. G. Omran and S. A. Sharhan, "Studying the effect of using low-discrepancy sequences to initialize populationbased optimization algorithms," Computational Opt. and Apps, vol. 56, no. 2, pp. 457-480, 2013.

[49] N. Henderson, D. M. Menezes and A. A. Sacco, "Computation of critical points of mixtures using particle swarm optimization with low-discrepancy sequences," Chemical Engineering Communications, vol. 202, no. 11, pp. $1478-1492,2015$.

[50] M. Richards and D. Ventura, "Choosing a starting configuration for particle swarm optimization," IEEE Int. Joint Conf. on Neural Networks, Budapest, vol. 3, pp. 2309-2312, 2004.

[51] P. Murugan, "Modified particle swarm optimisation with a novel initialisation for finding optimal solution to the transmission expansion planning problem," IET Generation, Transm. \& Dist, vol. 6, no. 11, pp. 1132-1142, 2012. 
[52] A. Gutierrez, M. Lanza and Barriuso, "Comparison of different PSO initialization techniques for high dimensional search space problems: A test with FSS and antenna arrays," in Proc. of the 5th European Conf. on Antennas and Propagation (EUCAP), pp. 965-969, 2011.

[53] R. Brits, A. P. Engelbrecht and V. Bergh, "A niching particle swarm optimizer," in Proc. of the 4th Asia-Pacific conf. on simulated evolution and learning, Av. Instituto Politécnico Nacional, México, MEXICO, vol. 2, pp. 692696, 2002.

[54] H. Jabeen, Z. Jalil and A. R. Baig, "Opposition based initialization in particle swarm optimization (O-PSO)," in Proc. of the 11th Annual Conf. Companion on Genetic and Evolutionary Computation Conf.: Late Breaking Papers, pp. 2047-2052, 2009.

[55] M. S. Norouzzadeh, M. R. Ahmadzadeh and M. Palhang, "PSO: A novel approach to effectively initializing particle swarm optimization," in 3rd Int. Conf. on Computer Science and Information Technology, pp. 705$709,2010$.

[56] J. Du, F. Zhang, G. Huang and J. Yang, "A new initializing mechanism in particle swarm optimization," in IEEE Int. Conf. on Computer Science and Automation Engineering, Shanghai, vol. 4, pp. 325-329, 2011.

[57] R. Ngamtawee and P. Wardkein, "Multi-band fir filter design using particle swarm optimization with minimax initialization," in 2012 9th Int. Conf. on Electrical Engineering/Electronics, Computer, Telecommunications and Information Technology, pp. 1-4, 2012.

[58] W. Gao, S. Liu and L. Huang, "Particle swarm optimization with chaotic opposition-based population initialization and stochastic search technique," Communications in Nonlinear Science and Numerical Simulation, vol. 17, no. 11, pp. 4316-4327, 2012.

[59] L. Yin, X. Hu and J. Zhang, "Space-based initialization strategy for particle swarm optimization," in Proc. of the 15th Annual Conf. Companion on Genetic And Evolutionary Computation (GECCO '13 Companion). Association for Computing Machinery, NY, USA, pp. 19-20, 2013.

[60] C. J. Wang, H. Fang, C. Wang, M. Daneshmand and H. Wang, "A novel initialization method for particle swarm optimization-based FCM in big biomedical data," in IEEE Int. Conf. on Big Data (Big Data), Santa Clara, CA, pp. 2942-2944, 2015.

[61] E. T. V. Zyl and A. P. Engelbrecht, "A subspace-based method for PSO initialization," in IEEE Symp. Series on Computational Intelligence, Cape Town, pp. 226-233, 2015.

[62] M. Corazza, D. Tollo, G. Fasano and R. Pesenti, "A novel initialization of PSO for costly portfolio selection problems, Working Paper Series, Università Ca," Working Paper Series, Università Ca' Foscari Venezia, Italy, vol. 4, pp. 1-27, 2015.

[63] M. Diez, A. Serani, C. Leotardi, E. F. Campana, D. Peri et al., A proposal of PSO particles' initialization for costly unconstrained optimization problems: orthoinit. In: Advances in Swarm Intelligence, Lecture Notes in Computer Science. vol. 8794. Basel, Switzerland: Springer, Cham, pp. 126-133, 2014.

[64] A. A. Yahya, A. Osman and M. S. El-Bashir, "Rocchio algorithm-based particle initialization mechanism for effective PSO classification of high dimensional data," Swarm and Evolutionary Computation, vol. 34, pp. 18-32, 2017.

[65] S. Elsayed, R. Sarker and C. A. C. Coello, "Sequence-based deterministic initialization for evolutionary algorithms," IEEE Transactions on Cybernetics, vol. 47, no. 9, pp. 2911-2923, 2017.

[66] H. Wang, Z. Wu, J. Wang, X. Dong, S. Yu et al., "A new population initialization method based on space transformation search," in Fifth Int. Conf. on Natural Computation, Tianjin, pp. 332-336, 2009.

[67] X. Dong, S. Yu, Z. Wu and Z. Chen, A hybrid parallel evolutionary algorithm based on elite-subspace strategy and space transformation search. In: High Performance Computing and Applications. Lecture Notes in Computer Science. vol. 5938. Heidelberg: Springer, pp. 139-145, 2010.

[68] M. Diez, A. Serani, C. Leotardi and E. F. Campana, "Dense orthogonal initialization for deterministic PSO: Orthoinit+," in Advances in Swarm Intelligence. Lecture Notes in Computer Science, Y. Tan, Y. Shi, B. Niu (eds.), vol. 9712. Basel, Switzerland: Springer, Cham, pp. 322-330, 2016.

[69] B. Xue, M. Zhang and W. N. Browne, "Particle swarm optimisation for feature selection in classification: Novel initialisation and updating mechanisms," Applied Soft Computing, vol. 8, pp. 261-276, 2014. 